Article

\title{
Implant Treatment in Atrophic Maxilla by Titanium Hybrid-Plates: A Finite Element Study to Evaluate the Biomechanical Behavior of Plates
}

\author{
María Prados-Privado ${ }^{1,2, *}$, Henri Diederich ${ }^{3}$ and Juan Carlos Prados-Frutos 4 \\ 1 Department Continuum Mechanics and Structural Analysis, Higher Polytechnic School, \\ Carlos III University, Avenida de la Universidad, 30, 28911 Leganés, Madrid, Spain \\ 2 Research Department, ASISA Dental, Calle José Abascal, 32, 28003 Madrid, Spain \\ 3 Private Practice, 51 Avenue Pasteur, L2311 Luxembourg, Luxembourg; hdidi@pt.lu \\ 4 Department of Medicine and Surgery, Faculty of Health Sciences, Rey Juan Carlos University, \\ Avenida de Atenas s/n, 28922 Alcorcón, Madrid, Spain; juancarlos.prados@urjc.es \\ * Correspondence: mprados@ing.uc3m.es; Tel.: +34-914-443-012
}

Received: 31 May 2018; Accepted: 24 July 2018; Published: 25 July 2018

\begin{abstract}
A severely atrophied maxilla presents serious limitations for rehabilitation with osseointegrated implants. This study evaluated the biomechanical and long-term behavior of titanium hybrid-plates in atrophic maxilla rehabilitation with finite elements and probabilistic methodology. A three-dimensional finite element model based on a real clinical case was built to simulate an entirely edentulous maxilla with four plates. Each plate was deformed to become accustomed to the maxilla's curvature. An axial force of $100 \mathrm{~N}$ was applied in the area where the prosthesis was adjusted in each plate. The von Mises stresses were obtained on the plates and principal stresses on maxilla. The difference in stress between the right and left HENGG-1 plates was 3\%, while between the two HENGG-2 plates it was 2\%, where HENGG means Highly Efficient No Graft Gear. A mean maximum value of $80 \mathrm{MPa}$ in the plates' region was obtained, which is a lower value than bone resorption stress. A probability cumulative function was computed. Mean fatigue life was 1,819,235 cycles. According to the results of this study, it was possible to conclude that this technique based on titanium hybrid-plates can be considered a viable alternative for atrophic maxilla rehabilitation, although more studies are necessary to corroborate the clinical results.
\end{abstract}

Keywords: atrophic maxilla; titanium hybrid-plates; finite element analysis; biomechanical analysis

\section{Introduction}

The reconstruction of an atrophic maxilla has always been a challenge [1] because of anatomical and clinical factors due to the serious limitations for conventional implant placement [2]. These limitations are related to the amount of bone, which remains insufficient for the conventional placement of a dental implant [3]. The maxillary bone volume has been classified, among other authors, by Cawood and Howel in five grades (I to V). Grades IV and V are considered as extreme atrophies [4]. The most common alternatives in atrophic maxilla rehabilitation are bone grafting [5], pterygoid [6] or zygomatic implants [7], bone regeneration (with or without mesh) [8,9], and finally, short implants [10].

Bone grafting is the most common technique in the reconstruction of an atrophic maxilla [2]. The goal of hard tissue augmentation is to provide an adequate bone volume for ideal implant placement and to support soft tissue for optimal esthetics and function. Zygomatic implants present a viable alternative for this kind of treatment given their design with self-tapping screw and the appropriate length as this kind of implant can be placed in the bone with very good quality and excellent mechanical behavior [2,7]. Pterygoid implants have the advantage of allowing anchorage 
in the pterygomaxillary region, eliminating the need for sinus lifts or bone grafts. Additionally, pterygoid implants can eliminate posterior cantilever and improve axial loading [2,11]. Finally, short implants are widely used and have demonstrated their efficiency on implant treatment in atrophic jaw and maxilla [12,13].

The first hybrid plates were introduced by G. Scortecci in July 2000 and were first used in the same year in a patient with a fractured atrophic mandible. They had a large base plate $(25,33$, or $43 \mathrm{~mm}$ long, 7, 9, or $12 \mathrm{~mm}$ wide) [14]. These kinds of plates can be adjusted to the maxilla curvature and put in the best place to maintain occlusal function [15].

There are technical differences between the hybrid plates employed and the sub-periosteal implants. The first difference is that the hybrid plates are made of titanium grade II and machined from a block, and the sub-periosteal implants are made of chrome cobalt and cast individually. The second difference is that hybrid plates are flexible and can be adjusted in situ while sub-periosteal implants are rigid and modeled using an initial impression of the bone site. Sub-periosteal implants can only be cemented to the prosthesis while hybrid plates have a screw connection. To use them, it is necessary to make a groove in the bone to receive the plates so that they may become osseointegrated, which are then fixed with osteosynthesis screws.

Hybrid plates are made of titanium grade II, which is the main $\mathrm{cp}$ Ti used for industrial dental implant applications [16]. It is recognized that titanium and its alloys are biomaterials with the best in vivo behavior [17]. Due to the excellent biocompatibility of this material, it is very common to use it for biomedical applications such as dental implants ad hybrid-plates [18]. This biocompatibility is provided by the following properties of titanium: low level of conductivity, high corrosion resistance, thermodynamic state at physiological $\mathrm{pH}$ values, and low ion-formation tendency in aqueous environments $[19,20]$.

In that sense, the main differences between hybrid plates and other alternatives to treat atrophic maxilla as pterygoid, zygomatic, or short implants are a titanium alloy. Implants are mostly manufactured by titanium alloy Ti6Al4V.

The protocol employed in this study is called Cortically Fixed @ Once (CF@O). It is an alternative to conventional implant placement for severe atrophied maxilla and mandible. This technique uses plates and pterygoid implants. Plates are fixed to the bone with osteosynthesis screws. There are four types of plates available that differ in size and morphology, although in this study, only two of them were used. This technique has its origins in basal implantology, which was developed by Dr. Scortecci in the early 1980s when he proposed the Diskimplant ${ }^{\circledR}$, a disc implant system that was inserted laterally, and which he refined over the next few years [21]. Several basal implants were developed during the 1980s and the 2000s with different geometric forms and with perforations over the surface to improve the blood supply around the implant [14].

In the last few decades, the finite element method (FEM) has become very popular in the field of biomechanics as it is a useful tool to numerically calculate aspects such as stresses and strains, and to evaluate the mechanical behavior of biomaterials and human tissues, considering the difficulty in making such an assessment in vivo [22,23].

Dental implants and their components including hybrid-plates are subjected to cyclic loads. Therefore, fatigue of materials is introduced in all dental rehabilitations. Results with a good accuracy are essential in dental studies as fatigue is very sensitive to many parameters [22].

Owing to the variety of techniques for atrophic maxillary implant rehabilitation, a new technique based on innovative hybrid titanium plates is described and numerically analyzed. The aim of this study was to evaluate the biomechanical and long-term behavior of CF@O plates on a completely edentulous and atrophic maxilla by employing a finite element analysis and a probabilistic fatigue approach. 


\section{Materials and Methods}

\subsection{Description of the Protocol}

The CF@O protocol is an alternative to the existing treatment of the atrophied maxilla and mandible. This technique is less invasive than the conventional procedures, and implants can be loaded with a definitive restoration after 6-10 days. Between the surgery and the definitive prosthesis, the patient has a provisional prosthesis, which is a fixed immediate loading prosthesis made of resin installed on plates.

This protocol does not need a sinus lift for the rehabilitation in cases of atrophied maxilla nor bone graft in maxilla and mandible and is based on both traditional implantology methods, combined with the most modern tools.

The Cortically Fixed @ Once protocol is applicable to edentulous maxillae and mandibles, and to unilateral and bilateral edentulism in maxilla and mandible. This protocol is indicated in the following assumptions [24]:

- $\quad$ Reduced bone volume in the upper and lower jaws such as stage D or E according to the Lekholm and Zarb classification of bone quality.

- Severely reduced vertical bone height over the trajectory of the mandibular canal in the lower jaw where there is insufficient vertical bone height to place conventional implants.

- Where short implants are not deemed justified, or in cases where bone reconstruction is not feasible.

- In very sharp dentoalveolar ridges.

This protocol can be used in patients aged between 35 and 90 years and is performed under local anesthesia. It can be done in nearly all cases of atrophy except in the case of egg shell everywhere in the maxilla and $10 \mathrm{~mm}$ of residential bone in the mandible. A stereolithographic model based on CT scan is made. After surgery, a temporary fixed bridge is employed. Amoxicillin is prescribed ( $2 \mathrm{~g}$ a day for 10 days) and in case of pain, ibuprofen 600 (1-3 g a day). Finally, there are no restrictions on food after one month after surgery.

The treatment plan starts with signed patient consent. Then, an open flap in the maxilla, as in this study, is made from the left tuberosity along the crest till the canine region. Two hybrid plates HENGG-1 and HENGG-2 are fixed with osteosynthesis screws and covered. The flap is then closed on the left and right with polytetrafluoroethylene polymer (PTFE) monofilament nonabsorbable suture.

Depending on the atrophy, three types of prosthesis are available: a metal acrylic for a big atrophy and a metal ceramic or zirconia when there is less atrophy with enough bone. Another point to consider is the contribution of the pterygoid implants, which contribute to prosthesis fixation.

From 2013, 155 patients between the ages of 38 and 85 (95 were female and 60 were male and 105 were in the maxilla and 45 in the mandible) were treated with the protocol detailed previously, resulting in three failures of plates in the maxilla and two in the jaw. These lost treatments were related to infection processes in the soft tissues. After a follow-up period of one year, there was a clinical and radiographical check to confirm that the plates were fixed and without complication.

The finite element analysis employed in this study simulated a real case of a 58-year-old female, with patient consistent, who wanted fixed teeth in the maxilla in a compromised bone. The treatment consisted of two pterygoid implants, four hybrid plates fixed with osteosynthesis screws, and a metal acrylic bridge ten days later [25]. In this instance, only the plates were analyzed.

\subsection{Plates}

The plates used in the CF@O protocol are very thin, lightweight, and highly flexible, and therefore may be adapted to any bone anatomy. In this study, the two plates employed are detailed in Figure 1: 


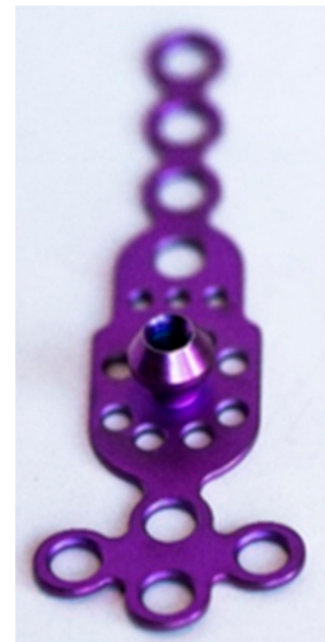

(a)

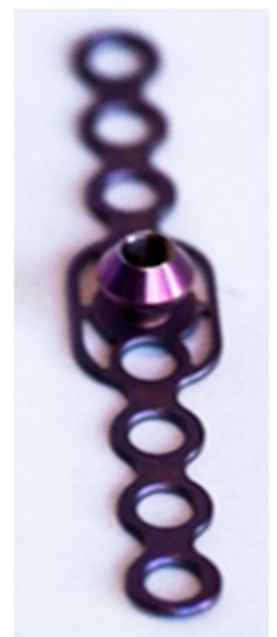

(b)

Figure 1. Plates employed in this study: (a) HENGG-1; (b) HENGG-2.

The HENGG-1 plate is appropriated for atrophied maxilla and is fixed with the zygomatic bone and the palate. The HENGG-2 plate is recommended for premaxilla, and the retromolar region in case of pencil mandible.

The plates are milled in a single piece and may be tilted in two axes to ensure that the implant fits the bone perfectly by manual shaping, making them isoelastic and able to mimic bone. They are minimally invasive and totally adjustable; they can be tilted at 90 degrees and the number of vents needed can be reduced as required, depending on the bone available at the site. They can also be twisted to fit the mandibular anatomy. They are stabilized and fixed by osteosynthesis screws, which give a strong cortical anchorage.

\subsection{Finite Element Reconstruction}

Geometric characteristics of the plates employed in the present study are shown in Figures 2 and 3.
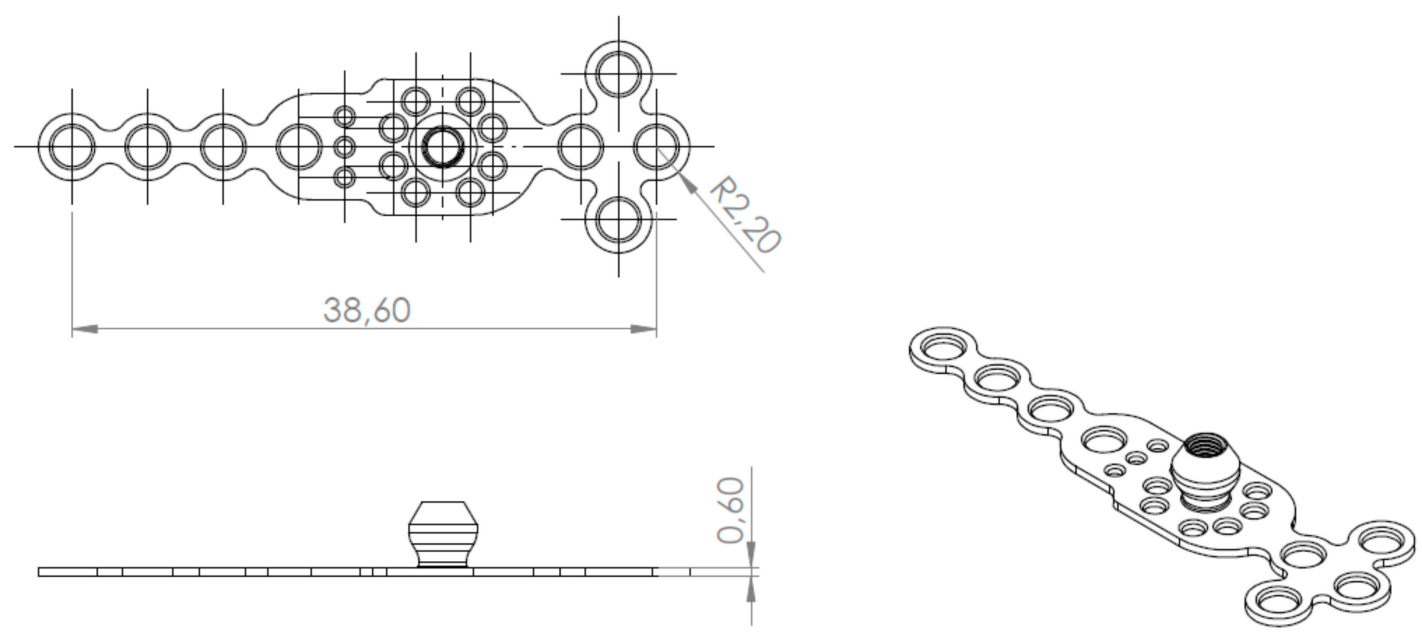

Figure 2. Plate HENGG-1. 

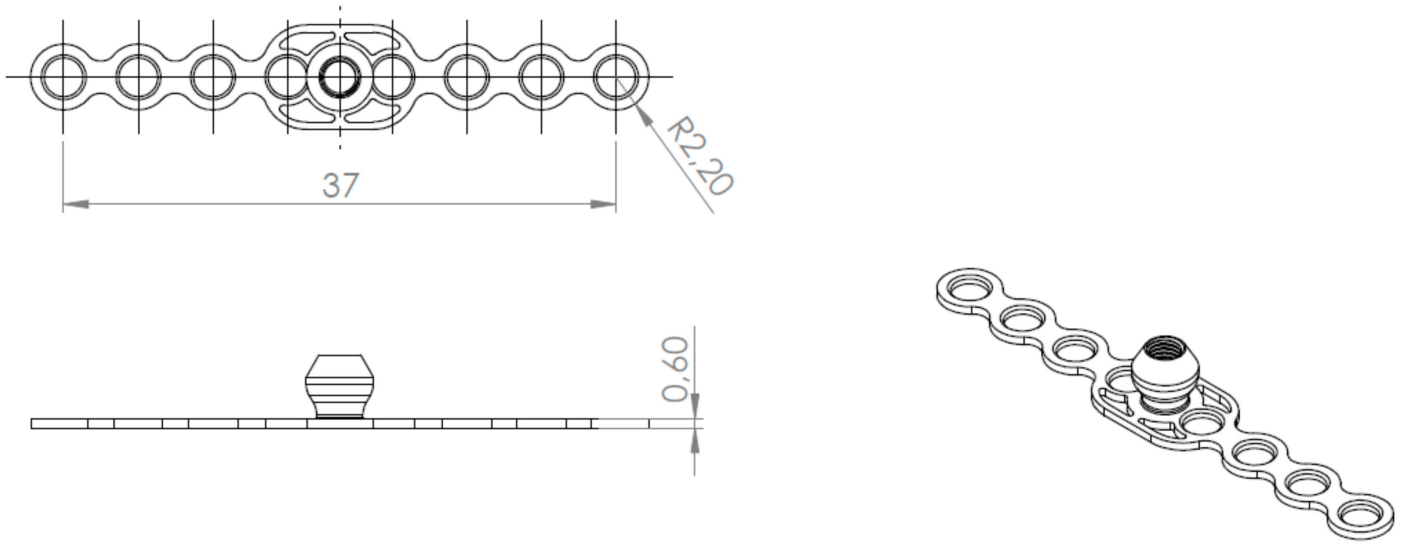

Figure 3. Plate HENGG-2.

All three-dimensional plates were adjusted to the anatomic characteristics of the maxilla (Figure $4 \mathrm{~b}$ ) as the common procedure in a real case (Figure $4 a$ ).

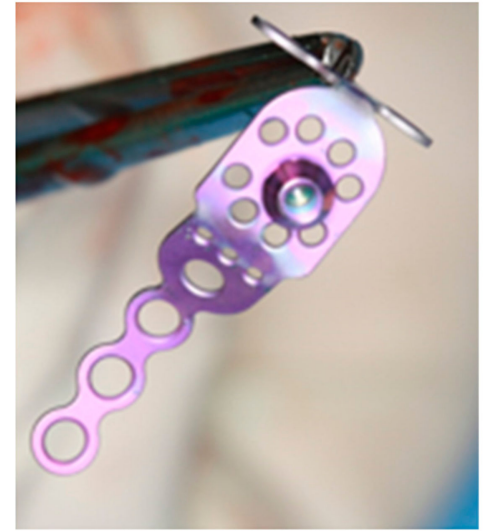

(a)

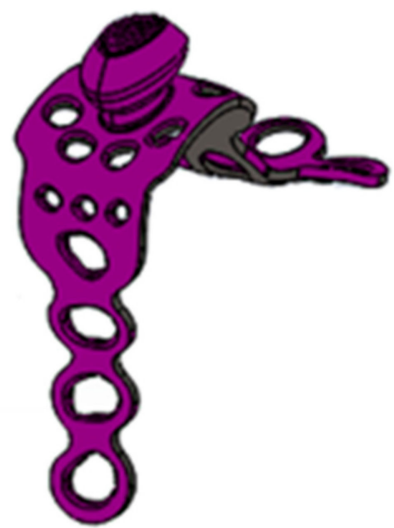

(b)

Figure 4. Plate adjusted to the anatomic characteristics of the maxilla: (a) Plate deformed before being placed in the patient; (b) three-dimensional model of a plate deformed.

The finite element model reproduced the case detailed previously, which is represented in Figure 5. Geometry of the maxilla was obtained using CT and transformed to the STL format. Slice increment was $0.5 \mathrm{~mm}$, according to other studies in the literature. All data in DICOM format were imported into the software package Mimics 10.0 (Materialize, Leuven, Belgium) for the construction of the 3-D model. Plate HENGG-1 was placed in the molar region and HENGG-2 in the premaxilla.

Finally, Figure 6 represents the three-dimensional finite element assembly employed to reproduce the clinical case detailed in this study.

The maxilla in STL format was imported into SolidWorks 2016 (Dassault Systèmes, SolidWorks Corp., Concord, MA, USA) where the assembly with the four plates was done (Figure 6). The trabecular bone was $1 \mathrm{~mm}$ thick [26]. 

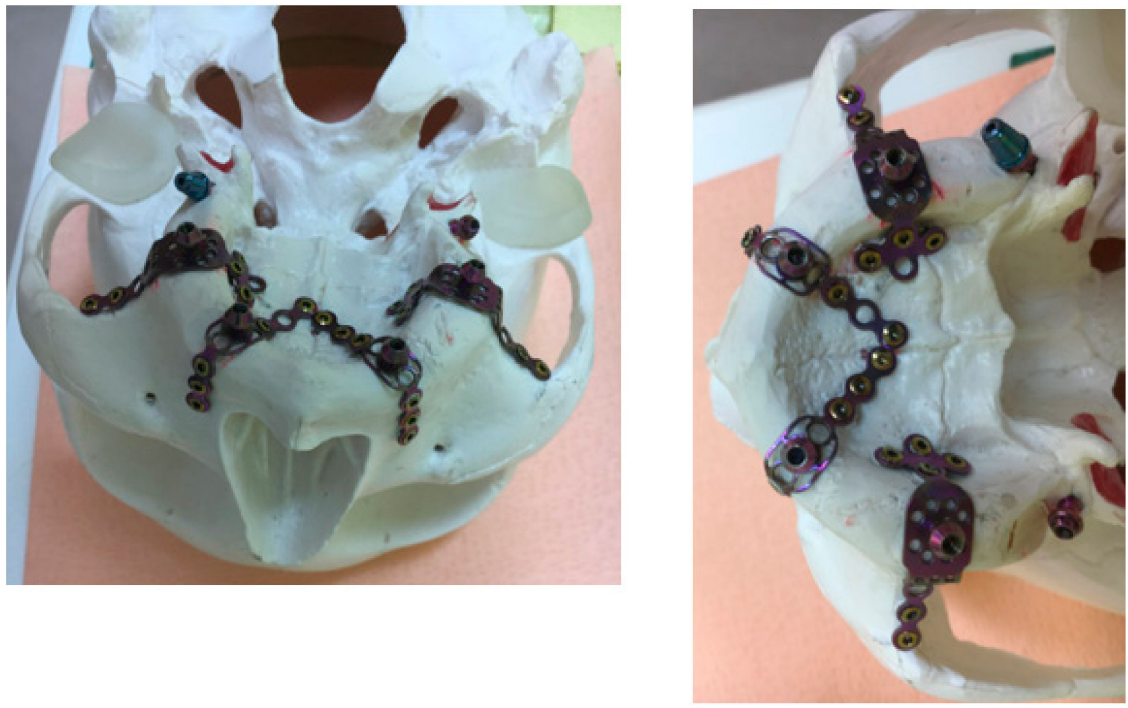

Figure 5. Model employed to reproduce in the finite element model.
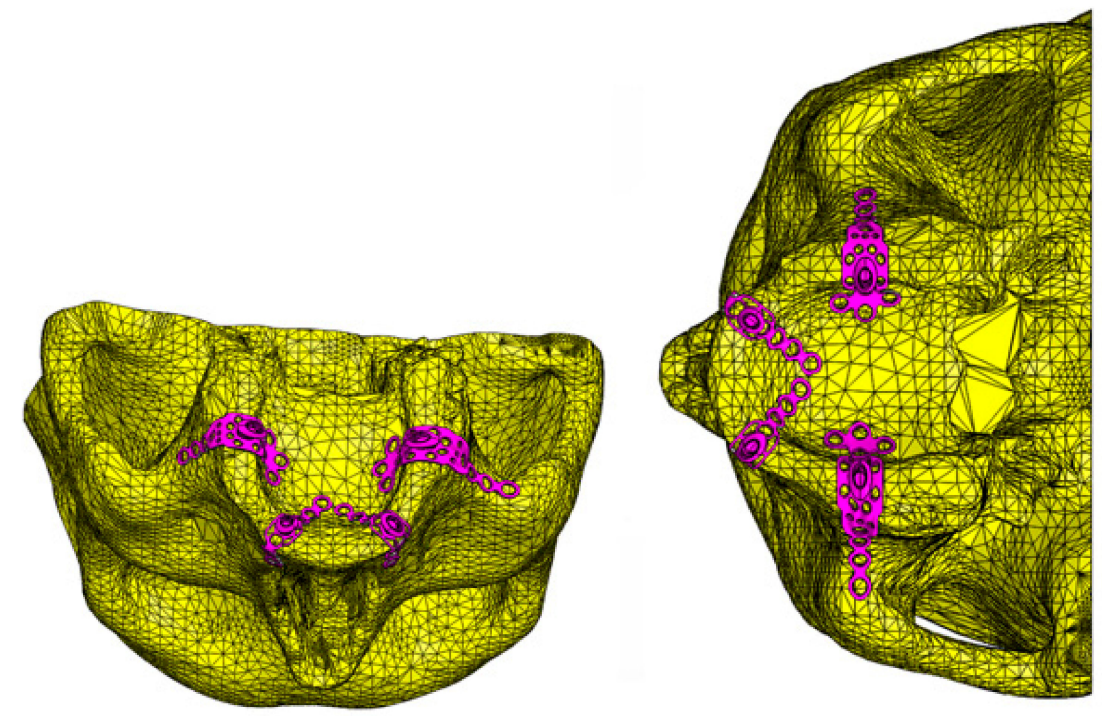

Figure 6. Finite element model employed in this study.

\subsection{Material Properties}

All materials were considered isotropic, linearly elastic, and homogeneous. The properties of the materials are detailed in Table 1.

Table 1. Material properties employed in this model.

\begin{tabular}{ccc}
\hline Title & Young's Modulus & Poisson's Ratio \\
\hline Plates (titanium grade II) [27] & $105 \mathrm{GPa}$ & 0.37 \\
Maxilla: cortical bone [26] & $13.7 \mathrm{GPa}$ & 0.3 \\
Maxilla: trabecular bone [26] & $1.37 \mathrm{GPa}$ & 0.3 \\
\hline
\end{tabular}

\subsection{Meshing}

Mesh generation was done in SolidWorks 2016 (Dassault Systèmes, SolidWorks Corp., Concord, MA, USA). All components were meshed with a fine mesh and all regions of stress concentration that 
were of interest were manually refined. The three-dimensional model presented a total of 432,404 nodes and 294,104 elements. The convergence criterion was a change of less than $5 \%$ in the von Mises stress in the model [28] (Figure 7).

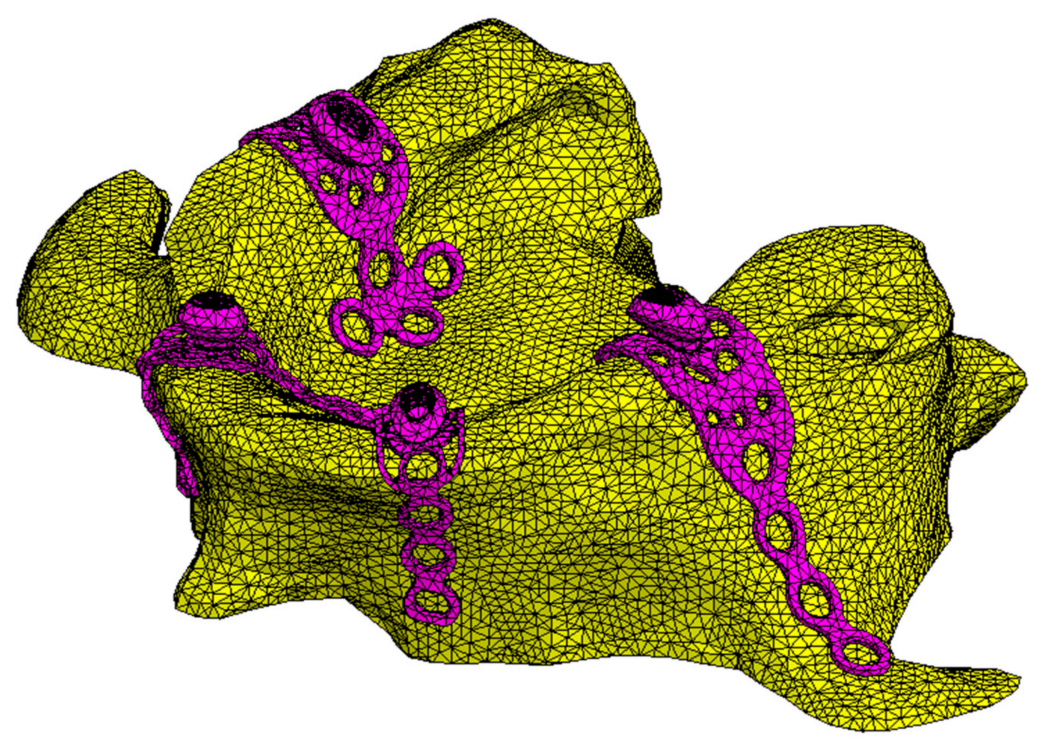

Figure 7. Finite element mesh (isometric view).

\subsection{Boundary Conditions and Loading Configuration}

The model was subjected to a rigid fixation restriction in the upper and lateral maxilla to prevent displacement in the $x, y$, and $z$ axes (Figure 8). Plates were in contact with the maxilla and a nonpenetration condition was also added to prevent interferences during the execution process between the plates and the maxilla.

A load of $100 \mathrm{~N}[29,30]$ was directly applied perpendicular to the area where the prosthesis was fixed to the plate as detailed in Figure 8.

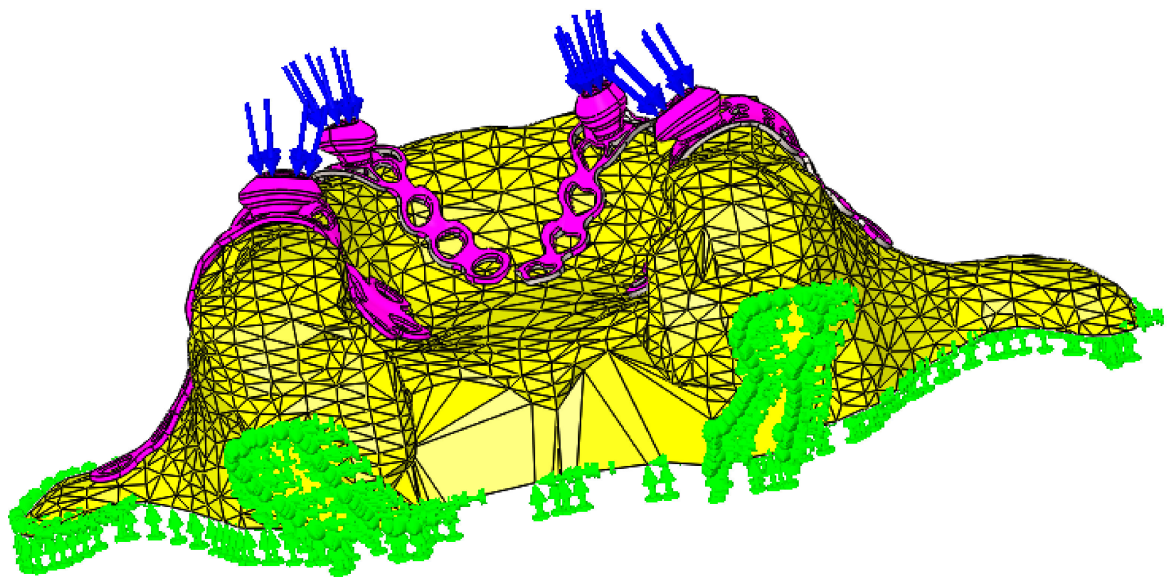

Figure 8. Three-dimensional posterior view of maxilla with load application and boundary conditions. Loads are represented in blue arrows and the rigid fixation restriction is represented in green.

\subsection{Probabilistic Fatigue Model}

In addition to the previous deterministic finite element analysis, a probabilistic fatigue model at the crack nucleation stage was also implemented. This stage is the most important regarding 
dental components and, hybrid plates, life, in particular [31]. As Riahi et al. detailed in their study, the probabilistic finite element method is a viable tool to estimate the influence of the stochastic properties of loads, material properties, and geometry on the response [32]. The methodology employed in this study was based on a cumulative damage B-model, which is constructed from the Probabilistic Finite Element Method (PFEM) results and computed for every random variable here considered: the Young's modulus (105 $\pm 10 \mathrm{GPa})$ and the applied loads (100 $\pm 10 \mathrm{~N})$ [31]. The input random variables considered in this study were handled via its first order Taylor series expansion. Once all the sensitivities of the random variables are known, it is possible to apply the mean and variance operator. All the sensitivities of the random fields involved, such as displacements field, strain field, and stress field can be obtained.

Bogdanoff and Kozin (B-K) created a number of probabilistic models of cumulative damage based on ideas from Markov chains. This study employed one they called the B-model of unit steps, for its simplicity and suitability to the physical description of the process of fatigue in the crack initiation stage. The hypotheses that serve as a basis for the expansion of the B-K unit step model are [33]:

(1) Damage cycles (DC) are repetitive and of constant severity.

(2) The levels of damage a component will go through until final failure are discrete $(1,2, \ldots, j, \ldots, b)$, and failure occurs at the last level of damage (b). This hypothesis merely discretizes the total life of the component in $b$ levels.

(3) The accumulation of damage that occurs in each DC depends only on the DC itself and the level of damage of the component at the start of said DC.

(4) The level of damage in each DC can only be increased from the occupied level at the beginning of said DC to the next immediate level.

As damage cycles have been defined as constant severity, the Probability Transition Matrix (P) will be unique and expresses the probability that each DC must be in the same level or the probability will jump to the next DC. This matrix depends on the $p_{j}$ (probability of remaining in the same DC) and $q_{j}$ (probability of jumping to the next DC) and is detailed in Equation (1).

$$
P=\left(\begin{array}{cccccc}
p_{1} & q_{1} & 0 & \ldots & 0 & 0 \\
0 & p_{2} & q_{2} & 0 & \ldots & 0 \\
0 & 0 & p_{3} & q_{3} & \ldots & 0 \\
\vdots & \vdots & \vdots & \vdots & \ddots & \vdots \\
0 & 0 & 0 & \cdots & p_{b-1} & q_{b-1} \\
0 & 0 & 0 & \cdots & 0 & 1
\end{array}\right)
$$

The new vector $p_{x}$ is a vector showing the distribution of damage levels for time $t=x$. Using the results of Markov chains, vector $p_{x}$ is:

$$
p_{x}=p_{x-1} P=p_{0} P^{x} \text { with } x=0,1,2 \ldots
$$

Finally, to compute the fatigue life estimators, Neuber's rule and a random formulation of the Coffin and Basquin-Manson expressions were employed. Neuber's rule relates the levels of elastic stress and strain obtained by a linear elastic analysis with actual levels of stress and strain, in accordance to the elastic-plastic behavior material [34].

Coffin, for the elastic component of deformations, and Basquin and Manson, for the elastic-plastic component, proposed a nonexplicit relationship between the fatigue life cycles in the nucleation stage of a component and the amplitudes of strain. This relation is shown in Equation (3)

$$
\frac{\Delta \varepsilon_{e p}}{2}=\frac{\sigma_{f}^{\prime}}{E}\left(2 N_{f}\right)^{b}+\varepsilon_{f}^{\prime}\left(2 N_{f}\right)^{c}
$$


where $\Delta \varepsilon_{e p}$ is the range of elastic-plastic strain suffered by the component at the crack initiation area; $\sigma_{f}^{\prime}$ is the fatigue resistance coefficient; $\varepsilon_{f}^{\prime}$ is the fatigue ductility coefficient; $b$ is the fatigue resistance exponent; $c$ is the fatigue ductility exponent; $E$ is the modulus of elasticity; and $N_{f}$ is the fatigue life cycles.

The materials properties necessary to solve this probabilistic model are detailed in Table 2:

Table 2. Material properties for the probabilistic model.

\begin{tabular}{cccc}
\hline Parameter & Value & Parameter & Value \\
\hline$\Delta \varepsilon_{e p}$ & $0.352 \times 10^{-2}$ & $\sigma_{f}^{\prime}$ & $0.0140 \times 10^{6}$ \\
$b$ & -0.1203 & $\varepsilon_{f}^{\prime}$ & 0.1701 \\
$c$ & -0.349 & & \\
\hline
\end{tabular}

\section{Results}

\subsection{Plates}

To obtain a correct clinical behavior, loads must be uniformly distributed throughout the four plates and transmit small stresses to the maxilla. Figure 9 shows the von Mises stress on the plates. Stress distribution along the plates is different because of the anatomical geometry of the maxilla, however, these differences on stress values are very small, as Figure 10 details.

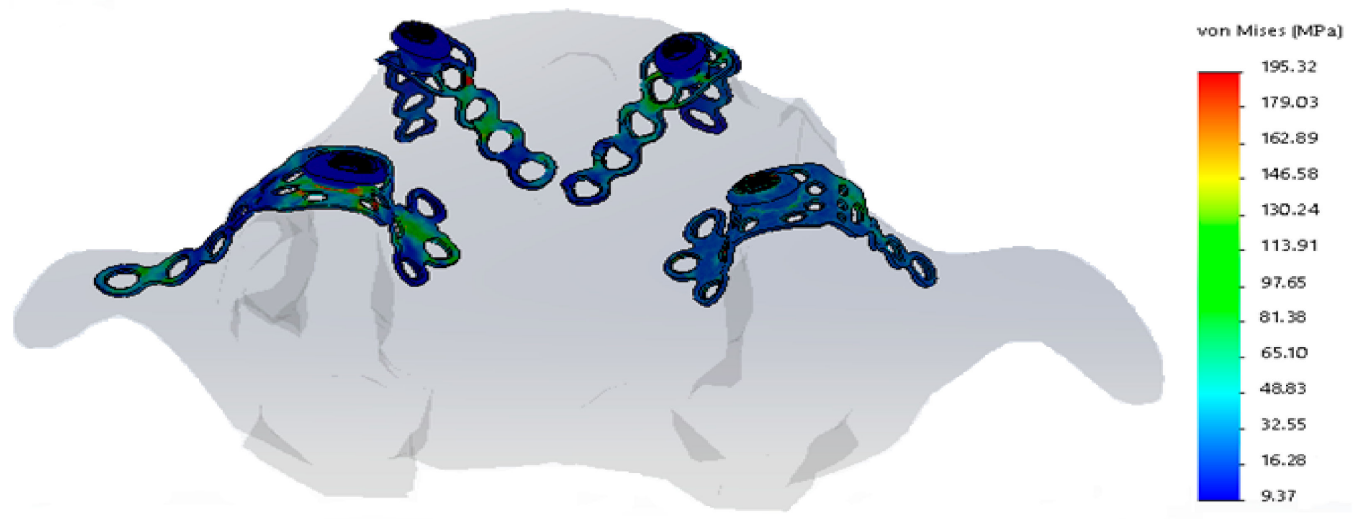

Figure 9. The von Mises stress on plates in MPa.

In Figure 9, the maximum von Mises stresses appeared around the area where the prosthesis was adjusted to the plate and the body of the plate. The right HENGG-1 plate supported a stress of $185 \mathrm{MPa}$, while the same plate on the left had a maximum von Mises stress of $179 \mathrm{MPa}$. Stress on the right HENGG-2 plate was $168 \mathrm{MPa}$ while in the plate placed on the left, it was $165 \mathrm{MPa}$.

According to Figure 10, the difference between the maximum von Mises stress in the HENGG-1 right and left plates was 3\%, while the difference between the HENGG-2 right and left plates was $2 \%$. 


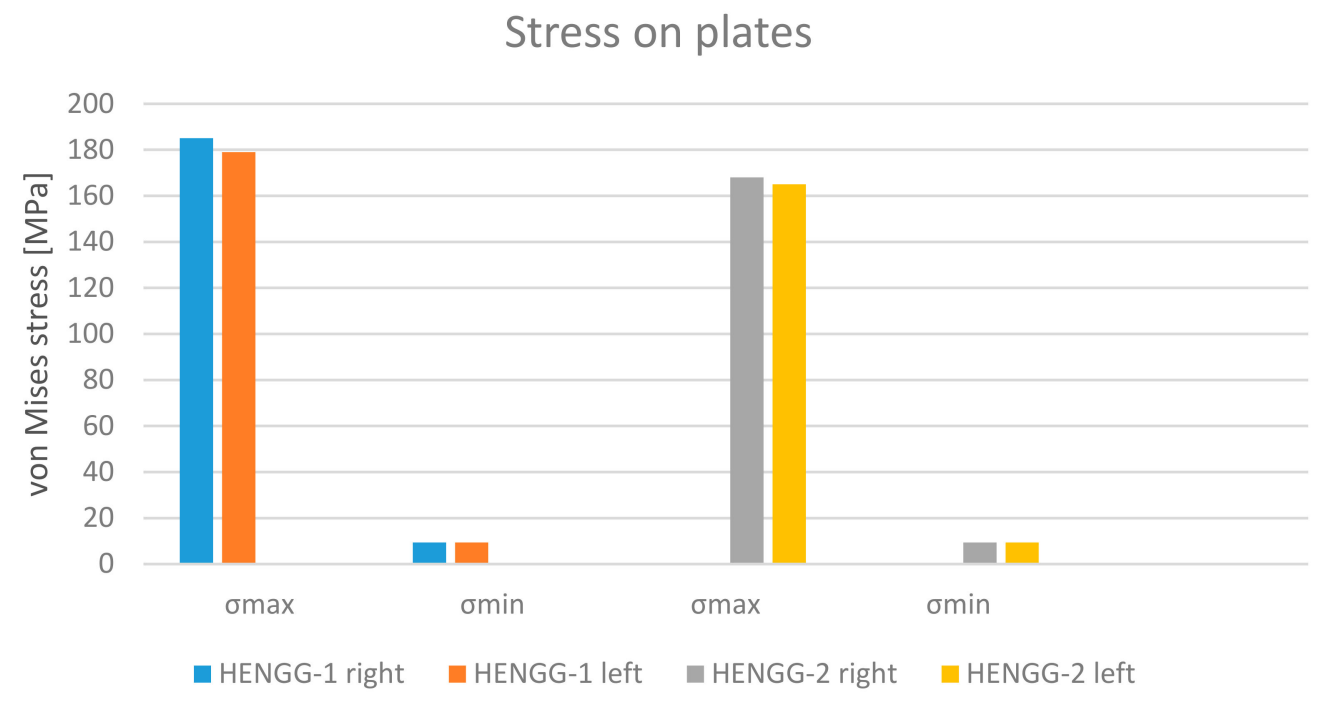

Figure 10. The von Mises stress values (in $\mathrm{MPa}$ ).

\subsection{Maxilla}

All plates showed similar distribution patterns of maximum principal stress over the atrophic maxilla. The difference in the principal stress value between the four regions in contact with plates was $5 \%$, with a mean maximum value of $80 \mathrm{MPa}$ in the plates' region.

\subsection{Long-Term Behavior}

Failure probability of the situation detailed previously was obtained by employing the probabilistic methodology. The expected life computed was 1,819,235 \pm 22.6 cycles. Then, the cumulative probability function was computed and represented in Figure 11.

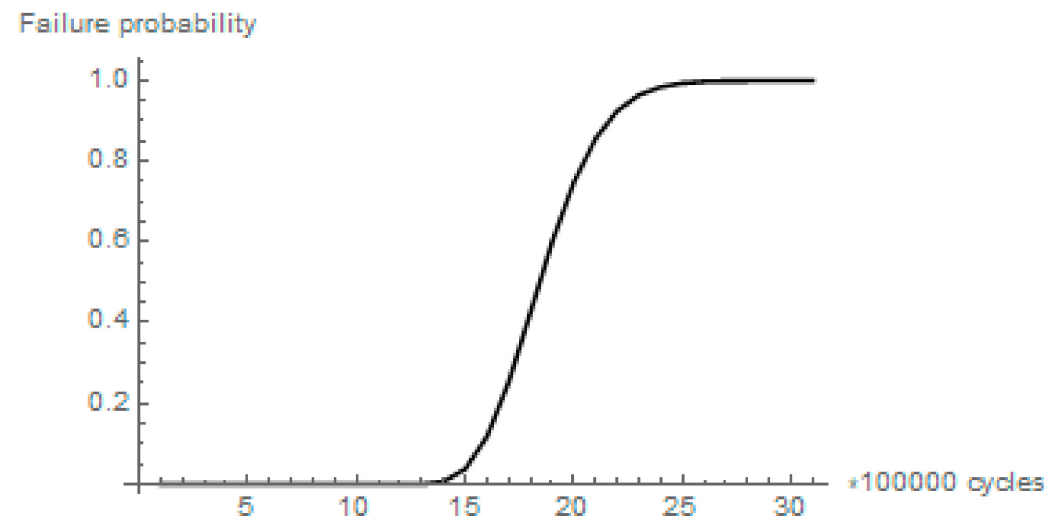

Figure 11. Cumulative probability function.

Figure 11 relates the probability of failure associated with each cycle load. As shown in the previous figure, the probability was equal to zero until 1,300,000 cycles.

\section{Discussion}

The biomechanical behavior of CF@O plates on a completely edentulous and atrophic maxilla was evaluated in the present study by employing finite element methods.

For a few years, there has been a trend towards minimally invasive implant treatment in very atrophic edentulous jaws and maxillae. The purpose of these concepts is to make an implant 
treatment with a shorter duration and smaller surgical risks [35]. The existence of insufficient bone can strongly influence the choice of the most appropriate rehabilitation in edentulous patients. There are several studies available in the literature that have employed different techniques to treat edentulous and atrophic maxilla, such as basal disk implants [36] or bone augmentation [37]. This study analyzed a new alternative based on titanium hybrid-plates. The accuracy of the results in numerical simulation studies depends on the precision of the model analyzed, the material properties, and the constraining conditions [38]. CT was used to model the geometry of the atrophic maxilla while the plates were provided by the manufacturer. A real clinical case with four titanium hybrid-plates in an atrophic maxilla was modeled and analyzed with the goal of knowing the biomechanical behavior of those plates.

This study had some assumptions and limitations. All materials were considered homogeneous, isotropic, and linearly elastic. Although these assumptions do not occur in clinical practice, they are common in finite element studies due to the challenges in establishing the properties of living tissues. These assumptions are consistent with other numerical studies [22,23,39]. In addition to these limitations, this work did not analyze the role of pterygoid implants as the goal was to study the biomechanical behavior of the plates. In that sense, ideal load distribution was considered.

The application of loads on the plates were supposed as an ideal transfer of loads from the prosthesis to that plate. If there is a good fit between the plate and the prosthesis, forces will be transmitted uniformly and as it was simulated and assumed in this study.

The ultimate strength in titanium grade II has been described as between 275 and $410 \mathrm{MPa}$ and the ultimate tensile strength as $344 \mathrm{MPa}$. From these finite element analysis results, the maximum von Mises stress values in plates were lower than the ultimate strength [27]. The difference between the maximum von Mises stress between the distal plates was $3 \%$, while the difference between the mesial plates was $2 \%$. This difference was due to the different geometry of the maxilla in each area.

Küçükkurt et al. [40] compared the biomechanical behavior of different sinus floor elevations for dental implant placement. Under the condition of vertical loadings, von Mises stress in mesial implants were lower than our results in the plates in the case of lateral sinus lifting. However, the plates analyzed in this study obtained lower von Mises stress values than the prosthetic distal cantilever application and short implant placement. Regarding the distal implants, our plates obtained lower stresses than the prosthetic distal cantilever.

Ihde et al. [41] numerically analyzed baseplate implants with a vertical load of $114.6 \mathrm{~N}$ and a horizontal load 17.1 $\mathrm{N}$ and obtained a maximum von Mises stress of $400 \mathrm{MPa}$. Ihde et al. [42] detailed the von Mises stress in basal implants depending on the bone interface contact (BIC) degree. In this study, the maximum von Mises stress values were between 649 and $190 \mathrm{MPa}$. In both cases, the titanium hybrid plates used and analyzed in this study obtained lower stresses.

Kopp et al. [43] calculated the distribution of stress when basal implants in the mandible were loaded at two different stages of bone healing. They applied a load of $450 \mathrm{~N}$ located in the middle between the left molar and left canine implant and oriented in a vertical direction. Under these conditions, the von Mises stress in the basal implants was around $565 \mathrm{MPa}$.

The ultimate stress is an important value to understand the limits of the behavior of a material. According to physiological limits (ultimate stress), overloading in the cortical bone has been described as $170 \mathrm{MPa}$ in compression and $100 \mathrm{MPa}$ in tension [44]. Dos Santos et al. [45] detailed in their study that cortical bone resorption occurred when stress was higher than $167 \mathrm{MPa}$. Based on these limits, the values observed in this model were lower than those considered physiologic to bone tissue. As bone cannot be considered a ductile material, von Mises stress cannot be calculated in the maxilla. In this case, principal stresses have to be employed and calculated although some published studies have not used this kind of stress $[39,45,46]$.

This is the reason why it is difficult to compare the results obtained in the atrophic maxilla of this study with the results provided in the bone in other published studies. 
A good biomechanical behavior of plates is understood when a homogeneous stress is transferred to the bone. In this case, the maximum difference between the region of all four plates was $5 \%$, meaning that the principal stress transferred from the plates to maxilla can be considered homogeneous.

Küçükkurt et al. [40] obtained a similar maximum principal stress in maxilla than our results in the case of short implant placement, and higher principal stress to our results in prosthetic distal cantilever application.

Clinical failures have generally been observed in the posterior maxilla region. Most of those failures were observed in bone types 3 and 4, with a highest probability of failures in bone type 4 [47]. According to the results obtained, the mean expected life in this case was 1,819,235 cycles. As Haug et al. detailed in their study [48], one year of in vivo service corresponds with, approximately, 200,000 cycles. Maló et al. obtained a satisfactory long-term outcome from patients with completely edentulous, severely atrophic maxillae supported by immediately loaded zygomatic implants alone, or in combination with conventional implants [49]. The same satisfactory results were detailed in Migliorança et al. who employed zygomatic implants placed lateral to the maxillary sinus and combined with conventional implants for a rehabilitation of the edentulous maxilla [50].

Further studies simulating these titanium hybrid-plates alternatives for atrophic maxilla and jaw that include dynamic forces that occur during chewing and consider the anisotropic and regenerative properties of bone are needed. Furthermore, some in vivo clinical trials are necessary to validate the model and to confirm the efficiency of this protocol. A numerical study of the combination of prosthesis-plates-implant under different functional conditions (bruxism and other parafunctions) just like the antagonist arcade is also necessary. Finally, a simulation of blood flow and bone regeneration around the plates is also necessary.

\section{Conclusions}

Based on the study results, it is possible to conclude that in terms of clinical application, the results indicate that titanium hybrid-plates proposed as an alternative to severe atrophic maxilla seems to have, from a mechanical point of view, a better behavior than conventional treatments such as prosthetic distal cantilever application and short implant placement. Titanium hybrid-plates distributed load to the maxilla with similar values as short implants but, with higher values than the prosthetic distal cantilever application. In any case, the resistance limits of bone and titanium were not exceeded. Long-term outcomes also seemed to be better than those clinical cases to treat atrophic maxilla. Finally, this technique can be considered as a viable alternative for atrophic maxilla rehabilitation, although more studies are necessary to corroborate the clinical results. As a clinical implication, this treatment allows the patient to be provided with functionally adequate prosthetic rehabilitation, which implies the recovery of their quality of life in a patient with a severe atrophy and, therefore, with an important challenge to a conventional implant treatment.

Author Contributions: M.P.-P. conceived, designed, and performed the analyses, evaluated the results, and wrote part of the paper. H.D. provided critical analysis. J.C.P.-F. provided critical analysis, interpretation of data, reviewed the literature, and wrote part of the paper.

Funding: This research was partially funded by Proclinic grant number A-285 and Instradent grant number A-274. Principal Researcher: Juan Carlos Prados-Frutos.

Conflicts of Interest: The authors declare no conflicts of interest.

\section{References}

1. Van der Mark, E.L.; Bierenbroodspot, F.; Baas, E.M.; de Lange, J. Reconstruction of an atrophic maxilla: Comparison of two methods. Br. J. Oral Maxillofac. Surg. 2011, 49, 198-202. [CrossRef] [PubMed]

2. Ali, S.; Karthigeyan, S.; Deivanai, M.; Kumar, A. Implant Rehabilitation For Atrophic Maxilla: A Review. J. Indian Prosthodont. Soc. 2014, 13, 196-207. [CrossRef] [PubMed]

3. Spencer, K. Implant based rehabilitation options for the atrophic edentulous jaw. Aust. Dent. J. 2018, 63, S100-S107. [CrossRef] [PubMed] 
4. Cawood, J.I.; Howell, R.A. A classification of the edentulous jaws. Int. J. Oral Maxillofac. Surg. 1988, 17, $232-236$. [CrossRef]

5. Chiapasco, M.; Zaniboni, M. Methods to Treat the Edentulous Posterior Maxilla: Implants With Sinus Grafting. J. Oral Maxillofac. Surg. 2009, 67, 867-871. [CrossRef] [PubMed]

6. Cucchi, A.; Vignudelli, E.; Franco, S.; Corinaldesi, G. Minimally Invasive Approach Based on Pterygoid and Short Implants for Rehabilitation of an Extremely Atrophic Maxilla. Implant Dent. 2017, 26, 639-644. [CrossRef] [PubMed]

7. Aparicio, C.; Manresa, C.; Francisco, K.; Claros, P.; Alández, J.; González-Martín, O.; Albrektsson, T. Zygomatic implants: Indications, techniques and outcomes, and the Zygomatic Success Code. Periodontol. 2000 2014, 66, 41-58. [CrossRef] [PubMed]

8. Gultekin, B.A.; Cansiz, E.; Borahan, M.O. Clinical and 3-Dimensional Radiographic Evaluation of Autogenous Iliac Block Bone Grafting and Guided Bone Regeneration in Patients With Atrophic Maxilla. J. Oral Maxillofac. Surg. 2017, 75, 709-722. [CrossRef] [PubMed]

9. Kaneko, T.; Nakamura, S.; Hino, S.; Norio, H.; Shimoyama, T. Continuous intra-sinus bone regeneration after nongrafted sinus lift with a PLLA mesh plate device and dental implant placement in an atrophic posterior maxilla: A case report. Int. J. Implant Dent. 2016, 2, 16. [CrossRef] [PubMed]

10. Alqutaibi, A.Y.; Altaib, F. Short dental implant is considered as a reliable treatment option for patients with atrophic posterior maxilla. J. Evid. Based Dent. Pract. 2016, 16, 173-175. [CrossRef] [PubMed]

11. Candel, E.; Peñarrocha, D.; Peñarrocha, M. Rehabilitation of the Atrophic Posterior Maxilla With Pterygoid Implants: A Review. J. Oral Implantol. 2012, 38, 461-466. [CrossRef] [PubMed]

12. Anitua, E.; Orive, G.; Aguirre, J.J.; Andía, I. Five-Year Clinical Evaluation of Short Dental Implants Placed in Posterior Areas: A Retrospective Study. J. Periodontol. 2008, 79, 42-48. [CrossRef] [PubMed]

13. Anitua, E.; Piñas, L.; Begoña, L.; Orive, G. Long-term retrospective evaluation of short implants in the posterior areas: Clinical results after 10-12 years. J. Clin. Periodontol. 2014, 41, 404-411. [CrossRef] [PubMed]

14. Scortecci, G.; Misch, C.; Benner, K. Implants and Restorative Dentistry; Martin Dunitz: London, UK, 2001.

15. Wu, C.; Lin, Y.; Liu, Y.; Lin, C. Biomechanical evaluation of a novel hybrid reconstruction plate for mandible segmental defects: A finite element analysis and fatigue testing. J. Cranio-Maxillofac. Surg. 2017. [CrossRef] [PubMed]

16. Sidambe, A. Biocompatibility of Advanced Manufactured Titanium Implants-A Review. Materials 2014, 7, 8168-8188. [CrossRef] [PubMed]

17. Torres, Y.; Lascano, S.; Bris, J.; Pavón, J.; Rodriguez, J.A. Development of porous titanium for biomedical applications: A comparison between loose sintering and space-holder techniques. Mater. Sci. Eng. C 2014, 37, 148-155. [CrossRef] [PubMed]

18. Suzuki, K.; Takano, T.; Takemoto, S.; Ueda, T.; Yoshiari, M.; Sakurai, K. Influence of grade and surface topography of commercially pure titanium on fatigue properties. Dent. Mater. J. 2018, 37, 308-316. [CrossRef] [PubMed]

19. Elias, C.N.; Lima, J.H.C.; Valiev, R.; Meyers, M.A. Biomedical applications of titanium and its alloys. JOM 2008, 60, 46-49. [CrossRef]

20. Natali, A.N. Dental Biomechanics, 1st ed.; Taylor \& Francis Group: London, UK, 2003; ISBN 0-415-30666-3.

21. Scortecci, G.; Bourbon, B. Dentures on the Diskimplant. Rev. Fr. Prothes. Dent. 1990, 13, 31-48.

22. Prados-Privado, M.; Bea, J.A.; Rojo, R.; Gehrke, S.A.; Calvo-Guirado, J.L.; Prados-Frutos, J.C. A New Model to Study Fatigue in Dental Implants Based on Probabilistic Finite Elements and Cumulative Damage Model. Appl. Bionics Biomech. 2017, 2017, 3726361. [CrossRef] [PubMed]

23. Ferreira, M.B.; Barão, V.A.; Faverani, L.P.; Hipólito, A.C.; Assunção, W.G. The role of superstructure material on the stress distribution in mandibular full-arch implant-supported fixed dentures. A CT-based 3D-FEA. Mater. Sci. Eng. C 2014, 35, 92-99. [CrossRef] [PubMed]

24. Agbaje, J.O.; Vrielinck, L.; Diederich, H. Rehabilitation of Edentulous Jaw Using Cortically Fixed at Once (Cf@O) Protocol: Proof of Principle. Biomed. J. Sci. Tech. Res. 2018, 5, 1-5. [CrossRef]

25. Diederich, H.; Junqueira, M.A.; Guimarães, S.L. Immediate Loading of an Atrophied Maxilla Using the Principles of Cortically Fixed Titanium Hybrid Plates. Adv. Dent. Oral Health 2017, 3, 1-3. [CrossRef] 
26. Bhering, C.L.B.; Mesquita, M.F.; Kemmoku, D.T.; Noritomi, P.Y.; Consani, R.L.X.; Barão, V.A.R. Comparison between all-on-four and all-on-six treatment concepts and framework material on stress distribution in atrophic maxilla: A prototyping guided 3D-FEA study. Mater. Sci. Eng. C 2016, 69, 715-725. [CrossRef] [PubMed]

27. Boyer, R.; Welsch, G.; Collings, E.W. Materials Properties Handbook: Titanium Alloys; ASM International: Materials Park, OH, USA, 1994.

28. Peixoto, H.E.; Camati, P.R.; Faot, F.; Sotto-Maior, B.; Martinez, E.F.; Peruzzo, D.C. Rehabilitation of the atrophic mandible with short implants in different positions: A finite elements study. Mater. Sci. Eng. C 2017, 80, 122-128. [CrossRef] [PubMed]

29. Shimura, Y.; Sato, Y.; Kitagawa, N.; Omori, M. Biomechanical effects of offset placement of dental implants in the edentulous posterior mandible. Int. J. Implant Dent. 2016, 2, 17. [CrossRef] [PubMed]

30. Arat Bilhan, S.; Baykasoglu, C.; Bilhan, H.; Kutay, O.; Mugan, A. Effect of attachment types and number of implants supporting mandibular overdentures on stress distribution: A computed tomography-based 3D finite element analysis. J. Biomech. 2015, 48, 130-137. [CrossRef] [PubMed]

31. Prados-Privado, M.; Prados-Frutos, J.C.; Calvo-Guirado, J.L.; Bea, J.A. A random fatigue of mechanize titanium abutment studied with Markoff chain and stochastic finite element formulation. Comput. Methods Biomech. Biomed. Eng. 2016, 19, 1583-1591. [CrossRef] [PubMed]

32. Riahi, H.; Bressolette, P.; Chateauneuf, A. Random fatigue crack growth in mixed mode by stochastic collocation method. Eng. Fract. Mech. 2010, 77, 3292-3309. [CrossRef]

33. Bogdanoff, J.; Kozin, F. Probabilistic Models of Cumulative Damage; Wiley: New York, NY, USA, 1985.

34. Neuber, H. Theory of Stress Concentration for Shear-Strained Prismatical Bodies With Arbitrary Nonlinear Stress-Strain Law. J. Appl. Mech. 1961, 28, 544-550. [CrossRef]

35. Wentaschek, S.; Hartmann, S.; Walter, C.; Wagner, W. Six-implant-supported immediate fixed rehabilitation of atrophic edentulous maxillae with tilted distal implants. Int. J. Implant Dent. 2017, 3, 35. [CrossRef] [PubMed]

36. Odin, G.; Misch, C.E.; Binderman, I.; Scortecci, G. Fixed Rehabilitation of Severely Atrophic Jaws Using Immediately Loaded Basal Disk Implants After In Situ Bone Activation. J. Oral Implantol. 2012, 38, 611-616. [CrossRef] [PubMed]

37. Del Fabbro, M.; Rosano, G.; Taschieri, S. Implant survival rates after maxillary sinus augmentation. Eur. J. Oral Sci. 2008, 116, 497-506. [CrossRef] [PubMed]

38. Van Staden, R.C.; Guan, H.; Loo, Y.C. Application of the finite element method in dental implant research. Comput. Methods Biomech. Biomed. Eng. 2006, 9, 257-270. [CrossRef] [PubMed]

39. Almeida, E.O.; Rocha, E.P.; Júnior, A.C.F.; Anchieta, R.B.; Poveda, R.; Gupta, N.; Coelho, P.G. Tilted and Short Implants Supporting Fixed Prosthesis in an Atrophic Maxilla: A 3D-FEA Biomechanical Evaluation. Clin. Implant Dent. Relat. Res. 2015, 17, e332-e342. [CrossRef] [PubMed]

40. Küçükkurt, S.; Alpaslan, G.; Kurt, A. Biomechanical comparison of sinus floor elevation and alternative treatment methods for dental implant placement. Comput. Methods Biomech. Biomed. Eng. 2017, 20, $284-293$. [CrossRef] [PubMed]

41. Ihde, S.; Goldmann, T.; Himmlova, L.; Aleksic, Z.; Kuzelka, J. Implementation of contact definitions calculated by FEA to describe the healing process of basal implants. Biomed. Pap. Med. Fac. Univ. Palacky Univ. Olomouc 2008, 152, 169-73. [CrossRef]

42. Ihde, S.; Goldmann, T.; Himmlova, L.; Aleksic, Z. The use of finite element analysis to model bone-implant contact with basal implants. Oral Surg. Oral Med. Oral Pathol. Oral Radiol. Endodontol. 2008, 106, $39-48$. [CrossRef] [PubMed]

43. Kopp, S.; Kuzelka, J.; Goldmann, T.; Himmlova, L.; Ihde, S. Modeling of load transmission and distribution of deformation energy before and after healing of basal dental implants in the human mandible. Biomed. Tech. Eng. 2011, 56, 53-58. [CrossRef] [PubMed]

44. Pérez, M.A.; Prados-Frutos, J.C.; Bea, J.A.; Doblaré, M. Stress transfer properties of different commercial dental implants: A finite element study. Comput. Methods Biomech. Biomed. Eng. 2012, 15, 263-273. [CrossRef] [PubMed] 
45. Dos Santos Marsico, V.; Lehmann, R.B.; de Assis Claro, C.A.; Amaral, M.; Vitti, R.P.; Neves, A.C.C.; da Silva Concilio, L.R. Three-dimensional finite element analysis of occlusal splint and implant connection on stress distribution in implant-supported fixed dental prosthesis and peri-implantal bone. Mater. Sci. Eng. C 2017, 80, 141-148. [CrossRef] [PubMed]

46. Gümrükçü, Z.; Korkmaz, Y.T.; Korkmaz, F.M. Biomechanical evaluation of implant-supported prosthesis with various tilting implant angles and bone types in atrophic maxilla: A finite element study. Comput. Biol. Med. 2017, 86, 47-54. [CrossRef] [PubMed]

47. Sevimay, M.; Turhan, F.; Kiliçarslan, M.A.; Eskitascioglu, G. Three-dimensional finite element analysis of the effect of different bone quality on stress distribution in an implant-supported crown. J. Prosthet. Dent. 2005, 93, 227-234. [CrossRef] [PubMed]

48. Haug, R.; Fattahi, T.; Goltz, M. A biomechanical evaluation of mandibular angle fracture plating techniques. J. Oral Maxillofac. Surg. 2001, 59, 1199-1210. [CrossRef] [PubMed]

49. Maló, P.; Nobre Mde, A.; Lopes, A.; Ferro, A.; Moss, S. Five-year outcome of a retrospective cohort study on the rehabilitation of completely edentulous atrophic maxillae with immediately loaded zygomatic implants placed extra-maxillary. Eur. J. Oral Implantol. 2014, 7, 267-281. [PubMed]

50. Migliorança, R.; Coppedê, A.; Dias Rezende, R.; de Mayo, T. Restoration of the edentulous maxilla using extrasinus zygomatic implants combined with anterior conventional implants: A retrospective study. Int. J. Oral Maxillofac. Implants 2011, 26, 665-672. [PubMed]

(C) 2018 by the authors. Licensee MDPI, Basel, Switzerland. This article is an open access article distributed under the terms and conditions of the Creative Commons Attribution (CC BY) license (http://creativecommons.org/licenses/by/4.0/). 